\title{
Idiopathic adult intussusception
}

\author{
Sanooj Soni, Philip Moss, Thiagarajan Jaiganesh*
}

\begin{abstract}
Intussusception is an uncommon cause of abdominal pain in adults and poses diagnostic challenges for emergency physicians, due to its varied presenting symptoms and time course. Diagnosis is thus often delayed and results in surgical intervention due to the development of bowel ischaemia. We report on a young patient who presented with an ileo-ileal intussusception in whom there were no underlying lesions identified as a causal factor.
\end{abstract}

\section{Case Report}

A 26-year-old male, with no prior medical history, presented to the emergency department with a 24-h history of bouts of severe colicky abdominal pain, worse in the left lower quadrant. The symptom had initially started with vomiting just prior to the abdominal pain. He subsequently developed some diarrhoea, further episodes of vomiting and began to feel unwell with a fever. He was unable to tolerate even oral fluids, which had prompted his presentation to the ED that morning. There was no episode of rectal bleeding. His temperature was $38^{\circ} \mathrm{C}$, pulse of 120 beats per minute and a respiratory rate of 28 breaths per minute. He remained normotensive and maintained good oxygen saturations. Examination revealed a soft abdomen but gross tenderness in the lower quadrants, worse in the left iliac fossa. There was no palpable mass, and rectal examination did not demonstrate any blood. Bowel sounds were present and there were no clinical signs of peritonitis. After blood investigations were sent, he was treated with intravenous paracetamol, hyoscine butylbromide and intravenous fluids. He was sent for an abdominal $x$-ray, which revealed a single dilated loop of small bowel $(3 \mathrm{~cm})$ in the central abdomen with scanty bowel gas elsewhere (Figure 1). He subsequently was given opioid analgesia as his pain was increasing in severity.

An arterial blood gas on air analysis revealed a respiratory alkalosis $\left(\mathrm{pH} 7.650, \mathrm{pCO}_{2} 2.33 \mathrm{kPa}, \mathrm{pO} 2\right.$ $14.0 \mathrm{kPa}$, base excess $1.5 \mathrm{mmol} / \mathrm{l}$ and bicarbonate 25.6 $\mathrm{mmol} / \mathrm{l})$. He had a raised lactate level of $3.5 \mathrm{mmol} / \mathrm{l}$. Other blood tests illustrated raised acute inflammatory

\footnotetext{
* Correspondence: jaiganesh@doctors.org.uk

St Georges Hospital, Blackshaw road, Tooting, London, SW17 OQT, UK
}

markers such as C-reactive protein of $231.7 \mathrm{ng} / \mathrm{ml}$, and a white cell count of $15.9 \times 10^{9} / 1$ with a neutrophil count of $13.7 \times 10^{9} / 1$. Given his extreme pain, fever and raised lactate level, a clinical diagnosis of intra-abdominal sepsis secondary to gut ischaemia was made and the patient referred to the surgical team. A preoperative CT scan of his abdomen revealed an ileo-ileal intussusception with several loops of dilated small bowel proximal to the intussusception (Figures 2 and 3). There was also a large amount of free fluid seen in the abdomen.

He underwent a laparotomy a few hours after his presentation to the ED. Three litres of serosanguinous fluid was found in his peritoneal cavity along with $20 \mathrm{~cm}$ of ischaemic small bowel. This portion of the small bowel was resected $(29 \mathrm{~cm}$ about $15 \mathrm{~cm}$ from the ileocaecal valve) and a primary end-to-end anastomosis was performed. He was transferred to the intensive care unit postoperatively for optimisation. He made a good recovery and was discharged from the hospital 5 days later. Histopathology results of the removed specimen confirmed an intussuscepted segment of small bowel, which demonstrated a spectrum of changes from mucosal ischaemia/infarction to transmural haemorrohagic infarction. There was no evidence of malignancy or any other pathological trigger/nidus, and therefore the aetiology of his intussusception was unknown.

\section{Discussion}

Abdominal pain, which comprises about 5 to 10 percent of emergency department (ED) visits, continues to pose diagnostic challenges for emergency physicians because of the wide range of differential diagnoses, including gastrointestinal, gynaecological, genitourinary and cardiopulmonary causes [1]. Adult intussusceptions poses a

\section{SpringerOpen $^{\circ}$}

(c) 2011 Soni et al; licensee Springer. This is an Open Access article distributed under the terms of the Creative Commons Attribution License (http://creativecommons.org/licenses/by/2.0), which permits unrestricted use, distribution, and reproduction in any medium, provided the original work is properly cited. 


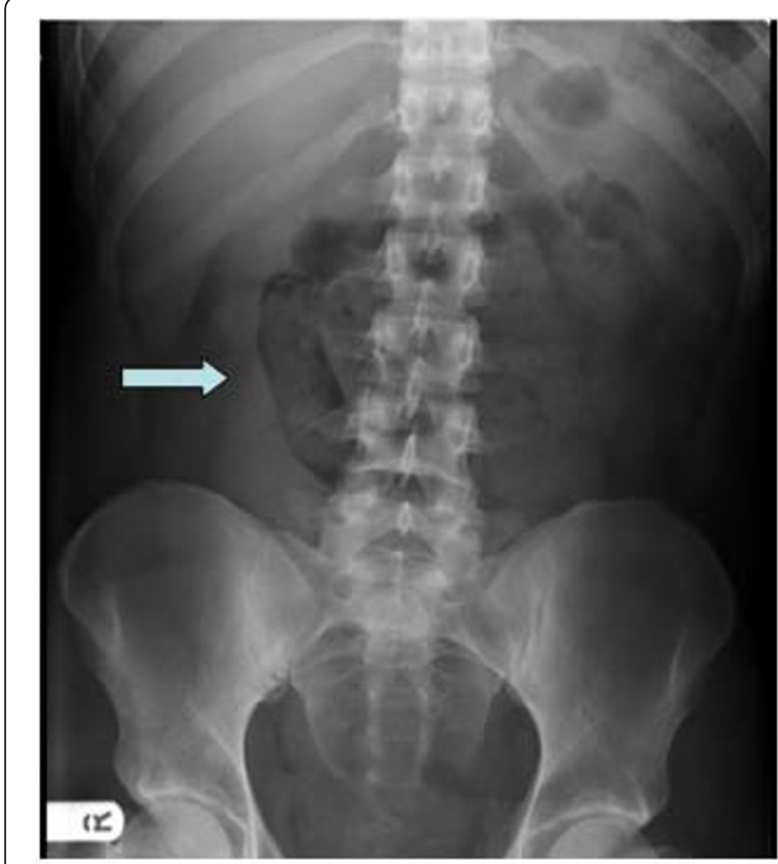

Figure 1 Plain abdominal x-ray showed a single loop of dilated small bowel (arrow key).

further challenge as they often present with nonspecific symptoms and run a chronic indolent course until bowel ischaemia supervenes [2].

Intussusceptions occur when one segment of the gastrointestinal tract (intussusceptum) telescopes into the lumen of an adjacent distal segment of the gastrointestinal tract (intussuscipiens). Adult intussusceptions represent only about $5 \%$ of all intussusceptions [3] and thus a

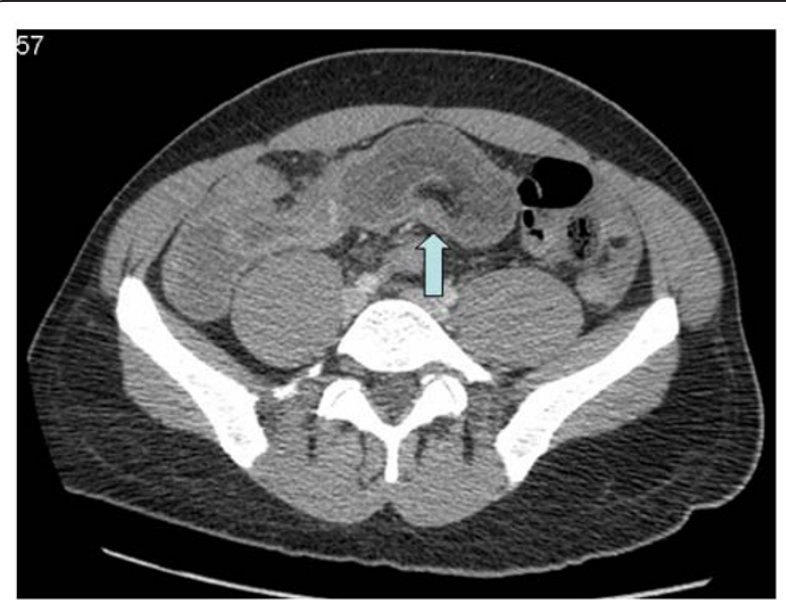

Figure 2 A sausage-shaped mass (arrow key) represents the intussuscepted segment. The fat density seen in the centre represents mesenteric fat.

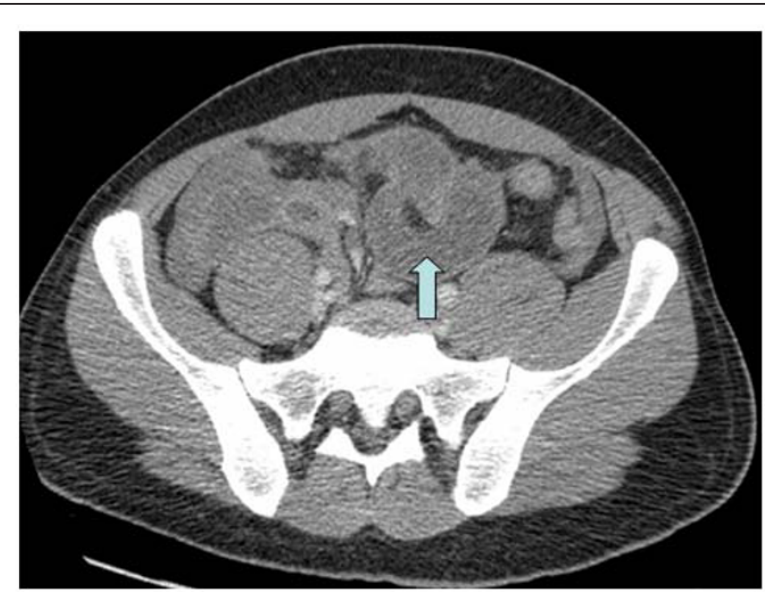

Figure 3 CT scan depicted the origin (arrow key) of the telescoping of the ileal segment.

rare cause of hospital admissions, accounting for only $0.005 \%[4]$.

Intussusception remains a rare clinical entity in adults. The mean age is 54.4 years, and the male-to-female ratio is 1:1.3 [5]. In adults, cases can be either acute or chronic, and abdominal pain is the most common symptom $(71-100 \%)$, followed by nausea and vomiting in $40-60 \%$ of the cases. Bleeding per rectum was seen in $4-33 \%$ of the cases [6]. This wide range is usually based on the site of the intussusception, with colonic ones bleeding more frequently than the ileal varieties. Acute abdominal pain with guarding is present in only about $50 \%$ of the cases [7]. Abdominal masses are palpable in less than $10 \%$ of patients [8].

A classification system exists according to the location of the intussusception. The four types are ileo-colic, ileo-ileo-colic, colo-colic and small bowel intussusception (jejuno-jejunal and ileo-ileal) [9]. In adults, often there is an underlying trigger or nidus for the intussusception in around 90-95\% of the cases [10]. The majority of lead points in the small intestine consist of benign lesions, such as benign neoplasms, Meckel's diverticuli, appendix and adhesions. Twenty-five percent of small bowel intussusceptions are caused by malignant lesions, whereas in the large bowel this number increases to around $50 \%$ [11].

Abdominal CT is the most useful diagnostic tool not only for detecting an intussusception with a diagnostic yield of around 78\%, but also helps in identifying the underlying cause [12]. The CT appearance of an intussusception is often a complex sausage-shaped soft tissue mass with an eccentric area of fat density contained within, which represents the mesenteric fat. The mesenteric vessels may be visible [13]. Plain abdominal $\mathrm{x}$-rays and ultrasound are of limited diagnostic value in adults. 
Treatment is almost always surgical in adults when compared to children and invariably leads to resection of the involved bowel segment with subsequent primary anastomosis. Gastroduodenal and coloanal intussusceptions are extremely rare and may require innovative surgical techniques [14]. Intermittent intussusceptions are known to occur and are often seen in either barium follow-through studies or on CT scans in patients with celiac disease, Crohn's disease, intestinal tumours and malabsorption syndromes as a result of abnormal intestinal contractions [15]. These transient ones can be managed conservatively in the absence of any severe abdominal symptoms.

Although, intussusceptions themselves have a good prognosis, it is often the nature of the lesion causing the intussusception on which the decisive factor is expected. Mortality for adult intussusceptions increases from 8.7\% for the benign lesions to $52.4 \%$ for the malignant variety [8]. In our case, no clear nidus or trigger was identified on histological examination of the resected segment.

\section{Conclusion}

Adult intussusception is a rare but well-recognized condition. A high index of suspicion and early diagnosis with a CT scan will identify patients requiring emergent surgery and thus prevent serious complications such as haemorrhage, intestinal gangrene and perforation.

\section{Consent}

Consent was obtained from the patient for publication of this case report and accompanying images.

\footnotetext{
Authors' contributions

SS - Wrote the first draft of the paper and coordinated the review of all the drafts. PM - Reviewed all drafts of the paper. TJ - Reviewed and commented on all the drafts of the paper and on all radiographic images. All authors read and approved the final manuscript.
}

\section{Competing interests}

The authors declare that they have no competing interests.

Received: 29 December 2010 Accepted: 16 March 2011

Published: 16 March 2011

\section{References}

1. Powers RD, Guertler AT: Abdominal pain in the ED: Stability and change over 20 years. Am J Emerg Med 1995, 13:301.

2. Begos DG, Sandor A, Modlin IM: The diagnosis and management of adult intussusception. Am J Surg 1997, 173:88-94

3. Agha FP: Intussusception in adults. AJR Am J Roentgenol 1986, 146:527-31.

4. Weilbaecher D, Bolin JA, Hearn D, Ogden W: Intussusception in adults. Review of 160 cases. Am J Surg 1971, 121:531-5.

5. Rathore MA, Andrabi SI, Mansha M: Adult intussusception-a surgical dilemma. J Ayub Med Coll Abbottabad 2006, 18(3):3-6.

6. Chang CC, Chen YY, Chen YF, Lin CN, Ten HH, Lou HY: Adult intssusceptions in Asians: clinical presentations, diagnosis, and treatment. J Gastroenterol Hepatol 2007, 22:1767-71.

7. Warshauer DM, Lee JK: Adult intussusception detected at CT or MR imaging: clinical-imaging correlation. Radiology 1999, 212(3):853-60.

8. Azar T, Berger DL: Adult intussusception. Ann Surg 1997, 226:134-8.
9. Williams H: Imaging and intussusception. Arch Dis Child Educ Pract Ed 2008, 93:30-36

10. Barussaud M, Regenet $N$, Briennon X, de Kerviler B, Pessaux P, KohnehSharhi N, Lehur PA, Hamy A, Leborgne J, le Neel JC, Mirallie E: Clinical spectrum and surgical approach of adult intussusceptions: a multicentric study. Int J Colorectal Dis 2006, 21(8):834-9, Epub 2005 Jun 11.

11. Weilbaecher D, Bolin JA, Hearn D, Ogden W: Intussusception in adults: Review of 160 cases. Am J Surg 1971, 121:531-5.

12. Huang BY, Warshauer DM: Adult intussusception: diagnosis and clinical relevance. Radiol Clin North Am 2003, 41(6):1137-51.

13. Gayer G, Zissin R, Apter S, Papa M, Hertz M: Pictorial review: adult intussusception-a CT diagnosis. Br J Radiol 2002, 75(890):185-90.

14. Yalarmathi S, Smith RC: Adult intussusception: case reports and review of literature. Postgrad Med J 2005, 81:174-177.

15. Catalano O: Transient small bowel intussusception: CT findings in adults. Br J Radiol 1997, 70:805-8.

doi:10.1186/1865-1380-4-8

Cite this article as: Soni et al:: Idiopathic adult intussusception.

International Journal of Emergency Medicine 2011 4:8.

\section{Submit your manuscript to a SpringerOpen ${ }^{\mathcal{D}}$ journal and benefit from:}

- Convenient online submission

- Rigorous peer review

- Immediate publication on acceptance

- Open access: articles freely available online

- High visibility within the field

- Retaining the copyright to your article

Submit your next manuscript at $>$ springeropen.com 